\title{
Comparison of colour discrimination and electroretinography in evaluation of visual pathway dysfunction in aretinopathic IDDM patients
}

\author{
Kevin J Hardy, Chris Fisher, Peter Heath, David H Foster, John H B Scarpello
}

\begin{abstract}
The slow progression of diabetic retinopathy makes it difficult to assess the effects of intervention therapy. There is thus a need for surrogate markers of visual change in diabetes. Colour vision tests and electroretinography (ERG) may be useful in this regard; yet little is known of their relative performance in the assessment of visual dysfunction in diabetes. The aim of the present study was to compare colour discrimination (100 hue test) and ERG indices (oscillatory potentials (OP) and pattern ERG (PERG)) in the evaluation of aretinopathic IDDM patients. Colour discrimination was abnormal in 10 aretinopathic IDDM patients when compared with nine age matched controls; mean square root 100 hue error scores were 10.38 (SD 2.89) versus $4 \cdot 77(1.87)$ respectively, $p<0 \cdot 01$. OP implicit times of the ERG were also abnormal; for example, for right eye, mean OP1 implicit time for diabetics versus OP1 implicit time for controls was $20 \cdot 1(2 \cdot 0)$ versus $18 \cdot 6(1 \cdot 4) \mathrm{ms}, p=0 \cdot 03$. Comparison of the two techniques suggested that the 100 hue test was more sensitive and more specific than ERG OP implicit times in the detection of diabetic visual dysfunction in these patients.
\end{abstract}

(Br f Ophthalmol 1995; 79: 35-37)

North Staffordshire

Royal Infirmary,

Princes Road,

Stoke-on-Trent

Department of

Endocrinology and

Diabetes

K J Hardy

J H B Scarpello

Department of Clinica Neurophysiology

C Fisher

P Heath

Department of Communication and Neuroscience, Keele University, Keele,

Staffs

D H Foster

Correspondence to: Dr K J Hardy, Department of Diabetes, Royal Infirmary of Edinburgh, Lauriston

of Edinburgh, Lauriston
Place, Edinburgh EH 3 9YW.

Accepted for publication

5 September 1994
The Diabetes Control and Complications Trial (DCCT) ${ }^{1}$ and 7 year follow up data from the Oslo Study ${ }^{2}$ have established that good glycaemic control slows progression of diabetic retinopathy. The size, complexity, and cost of the DCCT (estimated to be $\$ 168$ million) illustrate the difficulty of answering questions of intervention in diabetic retinopathy, where progression in retinal topographic features occurs over many years. This suggests a need for surrogate markers of visual change. Measures of visual pathway function may have such a role; visual pathway function assessed by either colour discrimination ability or electroretinography is abnormal in patients with insulin dependent diabetes mellitus (IDDM) with and without retinopathy. ${ }^{3-6}$ Moreover, in patients with retinopathy, electroretinography (ERG) may predict disease progression, ${ }^{7}$ and in aretinopathic IDDM patients, colour discrimination ability is affected by changes in glycaemic control. ${ }^{8}$
Although considerable work has been carried out with both ERG and colour vision measures in the assessment of visual function in IDDM, ${ }^{3-8}$ little is known about the relative performance of the two techniques. The aim of the present study was to compare colour discrimination performance (100 hue test) and electroretinography (implicit time and amplitude of pattern electroretinogram and oscillatory potentials) in detection of visual dysfunction in a group of aretinopathic IDDM patients. The results suggest that the 100 hue test is relatively more sensitive and more specific than ERG in the detection of visual pathway dysfunction in this group of patients.

\section{Patients and methods}

\section{PATIENTS}

Ten diabetic patients of mean age 26 (SD 5) years and with mean diabetes duration 8 (7) years were compared with nine healthy controls of mean age 26 (3) years. None of the patients or controls was receiving medication other than insulin, and none had a history of eye disease. None of the diabetic patients had evidence of retinopathy on fundal photography or fluorescein angiography.

\section{COLOUR DISCRIMINATION}

Colour discrimination ability was assessed by means of the Farnsworth-Munsell 100 hue test (Kollmorgen Corporation, Baltimore, MD, USA) used with a brighter light source than previously to improve the separation of performances by diabetic patients and controls. ${ }^{6}$ Briefly, each subject was tested uniocularly under a stimulated North Sky light of illuminance $1680 \mathrm{~lx}, \mathrm{CIE}$ coordinates $\mathrm{X}=0.3198$, $\mathrm{Y}=0.3282$, and correlated colour temperature $=6127 \mathrm{~K}$ (Northlight, Thorn EMI Lighting, London, UK) according to the original instructions ${ }^{9}$ and using the original Farnsworth scoring convertion. ${ }^{9}$

\section{ELECTRORETINOGRAPHY}

Electroretinograms were recorded under standardised conditions using a Neuropak 4 machine evoked potential averager (Nikon Kohden, Tokyo, Japan). After administration of $1 \%$ amethocaine eye drops (Minims I, Smith \& Nephew Pharmaceuticals, Romford, UK), DTL fine fibre electrodes (Unnamed, 
Table 1 Comparison of implicit time (latency) (mean (SD)) for N35, P55, and N95 waves and interpeak amplitudes N35-P55 and P55-N95 (mean (SD)) of the pattern electroretinogram in 10 diabetic patients and nine age matched controls

\begin{tabular}{|c|c|c|c|}
\hline & Diabetics & Controls & p Value \\
\hline \multicolumn{4}{|l|}{ Implicit time (ms): } \\
\hline $\begin{array}{l}\text { N35 } \\
\text { P55 } \\
\text { N95 }\end{array}$ & $\begin{array}{l}31 \cdot 4(2 \cdot 2) \\
54.6(1 \cdot 3) \\
94.7(6 \cdot 8)\end{array}$ & $\begin{array}{l}30 \cdot 9(2 \cdot 2) \\
54 \cdot 7(2 \cdot 7) \\
96 \cdot 1(6 \cdot 4)\end{array}$ & $\begin{array}{l}0.4 \\
0.4 \\
0.5\end{array}$ \\
\hline Left eye & & & \\
\hline $\begin{array}{l}\text { N35 } \\
\text { P55 }\end{array}$ & $\begin{array}{l}31.5(2.3) \\
54.8(1.9)\end{array}$ & $\begin{array}{l}31.3(2.7) \\
54.9(2.3)\end{array}$ & $\begin{array}{l}0.3 \\
0.4\end{array}$ \\
\hline $\begin{array}{l}\text { N95 } \\
\text { Amplitude }(\mu V) \text { : }\end{array}$ & $97 \cdot 3(7 \cdot 2)$ & $100 \cdot 0(6 \cdot 8)$ & 0.3 \\
\hline $\begin{array}{l}\text { Right eye } \\
\text { N35-P55 } \\
\text { P55-N95 }\end{array}$ & $\begin{array}{l}2.88(1.06) \\
4.56(1.83)\end{array}$ & $\begin{array}{l}2.78(0.73) \\
4.63(1.21)\end{array}$ & $\begin{array}{l}0.3 \\
0.4\end{array}$ \\
\hline $\begin{array}{l}\text { Left eye } \\
\text { N35-P55 } \\
\text { P55-N95 }\end{array}$ & $\begin{array}{l}3 \cdot 17(1 \cdot 43) \\
4 \cdot 81(2 \cdot 38)\end{array}$ & $\begin{array}{l}2.50(0.63) \\
4.46(0.80)\end{array}$ & $\begin{array}{l}0.1 \\
0.2\end{array}$ \\
\hline
\end{tabular}

Farnham, UK) were introduced into the conjunctival space underlying the lower eyelids, and for each eye, recordings made with reference to a $9 \mathrm{~mm}$ silver-silver chloride disc electrode located at the respective outer canthus. An earth lead was placed in the recommended position on the patient's forehead. ${ }^{10}$

\section{PATTERN ERG}

The pattern ERG was recorded with standardised background illumination in response to contrast of black and white squares viewed from $1.2 \mathrm{~m}$ where they subtended an angle of $12 \times 16$ degrees. Checks of 33 arcmin were alternated at $3 \mathrm{~Hz}$, and 300 responses averaged. The N35, P55, and N95 waves were identified, and peak latencies, and N35-P55 and P55-N95 interpeak amplitudes were measured by an experienced neurophysiologist.

\section{OSCILLATORY POTENTIALS}

After the pupils were dilated with $1 \%$ tropicamide, the subject was dark adapted for 15 minutes. Oscillatory potentials (OP) were recorded to flash stimuli generated by a Grass photic stimulator positioned $20 \mathrm{~cm}$ from the subject's eyes. After a conditioning flash, responses to four further flashes at 15 second intervals were averaged and peak latencies and interpeak amplitudes were measured. For the first $\mathrm{OP}$, the trough was extended horizontally to the ascending limb of the next potential, and the height of the perpendicular from base to peak was measured as the amplitude. ${ }^{7}$ For subsequent potentials, the troughs before and after

Table 2 Comparison of implicit time (ms) (mean (SD)) of first four oscillatory potentials in 10 diabetic patients and nine age matched controls

\begin{tabular}{|c|c|c|c|}
\hline & Diabetics & Controls & p Value \\
\hline $\begin{array}{l}\text { OP1, right eye } \\
\text { OP1, left eye } \\
\text { OP2, right eye } \\
\text { OP2, left eye } \\
\text { OP3, right eye } \\
\text { OP3, left eye } \\
\text { OP4, right eye } \\
\text { OP4, left eye }\end{array}$ & $\begin{array}{l}20 \cdot 1(2 \cdot 0) \\
20.9(1.6) \\
28.1(0.9) \\
27.8(1.3) \\
33.3(1.6) \\
32.3(3.1) \\
40.3(2 \cdot 2) \\
40.8(1.8)\end{array}$ & $\begin{array}{l}18.6(1.4) \\
18.9(1.5) \\
26.2(2 \cdot 8) \\
26.1(1.5) \\
32.6(2.5) \\
32.6(1.1) \\
39.2(2 \cdot 1) \\
39.4(2.2)\end{array}$ & $\begin{array}{l}0.03 \\
0.03 \\
0.01 \\
0.02 \\
0.09 \\
0.3 \\
0.06 \\
0.06\end{array}$ \\
\hline
\end{tabular}

Table 3 Comparison of peak amplitude $(\mu V)$ of the first four oscillatory potentials in 10 diabetic patients and nine age matched controls

\begin{tabular}{|c|c|c|c|}
\hline & Diabetics & Controls & p Value \\
\hline OP1, right eye & $14.9(10 \cdot 8)$ & $10 \cdot 1(6 \cdot 1)$ & 0.2 \\
\hline OP1, left eye & $14.6(10 \cdot 8)$ & $12.3(5.5)$ & $0 \cdot 3$ \\
\hline OP2, right eye & $19 \cdot 1(12 \cdot 8)$ & $24 \cdot 2(10 \cdot 5)$ & $0 \cdot 2$ \\
\hline OP2, left eye & $18 \cdot 2(19.4)$ & $29 \cdot 0(9 \cdot 1)$ & 0.01 \\
\hline OP3, right eye & $18.7(11.8)$ & $25 \cdot 1(9 \cdot 3)$ & 0.08 \\
\hline OP3, left eye & $20.6(16.4)$ & $26.5(8.0)$ & 0.04 \\
\hline OP4, right eye & $18 \cdot 3(12 \cdot 5)$ & $13.4(5 \cdot 5)$ & 0.06 \\
\hline OP4, left eye & $19 \cdot 8(15.0)$ & $14 \cdot 4(4 \cdot 5)$ & 0.5 \\
\hline
\end{tabular}

the potential were joined and a perpendicular was dropped from the peak of the wave to this line. The length of the perpendicular was taken as the amplitude of that OP. ${ }^{7}$

STATISTICAL ANALYSIS

Results of the 100 hue test are positively skewed so a square root transformation was performed as recommended by Kinnear. ${ }^{11}$ The transformed data were then compared with Student's $t$ test.

\section{Results}

COLOUR DISCRIMINATION

Colour discrimination ability was significantly worse in the diabetic patients compared with controls. Mean square root 100 hue error score (1 SD) for the diabetic group was $10 \cdot 38(2 \cdot 89)$ versus $4.77(1.87)$ for controls, $\mathrm{p}<0.01$.

\section{PATTERN ERG}

For the pattern ERG, there were no significant differences between diabetic patients and controls in implicit times of the N35, P55, and N95 waves or in the interpeak amplitudes, N35-P55 and P55-N95 (Table 1).

\section{OSCILLATORY POTENTIALS}

Oscillatory potential implicit times, particularly for the first and second potentials, were significantly delayed in the diabetic group (Table 2).

Some of the differences in OP amplitudes reached only borderline statistical significance, and the lack of a general trend in the data suggested that the biological significance of these results was doubtful (Table 3).

\section{COLOUR DISCRIMINATION VERSUS OP IMPLICIT TIME}

Mean square root 100 hue error score for controls in this study was 4.77 (SD 1.87), giving a normal range of between 1.03 and 8.51 (which is similar to previously published norms ${ }^{12}$ ). Against this criterion, $90 \%$ of the diabetic patients in this study had 100 hue error scores outside the normal range. By contrast, no control had a 100 hue error score outside the normal range.

With respect to the implicit times of the first and second OPs (the best ERG measures for distinguishing diabetic patients from controls 
in this study), only $40 \%$ of diabetic patients had OP implicit times outside the normal (mean (2 SD)) range. Moreover, one normal subject had an OP implicit times outside this range.

RELATIÓN BETWEEN 100 HUE ERROR SCORE AND OP IMPLICIT TIME

To produce a single value for OP implicit time for each patient, implicit times for each $\mathrm{OP}^{1-4}$ were normalised and then averaged. Normalisation was achieved by expressing each OP implicit time as a percentage of the mean for the control group. With this procedure, no significant correlation between abnormalities in the 100 hue test and OP latency emerged.

\section{Discussion}

This study confirms abnormalities of visual processing in young uncomplicated, IDDM patients, without overt retinopathy. Colour discrimination and OP implicit times were both abnormal in such patients when compared with healthy, age matched controls.

Unlike Bresnick et $a{ }^{7}{ }^{7}$ we did not demonstrate an abnormality of OP amplitude. But Bresnick studied patients with established, moderately severe, background retinopathy whereas patients in the present study were free from retinopathy. OP amplitude, which is correlated with level of retinopathy, ${ }^{13}$ may become abnormal only after onset of retinopathy or with a certain severity of retinopathy.

The pattern ERG appears to be less sensitive to visual dysfunction in aretinopathic diabetic patients. Like Jenkins, ${ }^{4}$ we found the pattern ERG did not show significant abnormalities and though Coupland ${ }^{14}$ found abnormalities in the pattern electroretinogram, this was only in patients with retinopathy; in this study, the subgroup of patients defined as having no retinopathy included patients with up to five microaneurysms which may be regarded as early background retinopathy. In the present study none of the patients had any evidence of retinopathy.

The data from this study suggest that the 100 hue test was relatively more sensitive and relatively more specific than OP implicit time. The magnitude of the errors in the diabetic patients compared with non-diabetics suggest that false positive results with the 100 hue test in the diabetic group are unlikely; similar comparisons between the scores for the control group and published norms ${ }^{12} 15$ suggest that there is a little likelihood of false negative results with the 100 hue test among the controls. If it is assumed that visual pathway dysfunction was ubiquitous among the diabetic patients $(90 \%$ had abnormal colour discrimination) then, the 100 hue test was $90 \%$ sensitive and $100 \%$ specific, whereas ERG OPs were $40 \%$ sensitive and $60 \%$ specific.
There are two caveats to this, however. The first is that without a general standard it is not possible to say with certainty what is the true prevalence of visual dysfunction among diabetic patients, and the second is that the 100 hue test and ERG OP implicit time may be measuring different aspects of visual pathway function, which is supported by the lack of correlation between the results of the two tests.

Even with the small numbers studied, significant differences were present between diabetic patients and non-diabetic controls both for colour discrimination and ERG OP implicit time, and in relative terms the 100 hue test was superior. Moreover, if a test is to be used as an indicator of the adequacy of glycaemic control, it would be advantageous if differences were obvious with relatively small numbers of patients. It is difficult to compare sensitivity and specificity when a general standard has not been established. On the basis of these results, colour discrimination measurements using the 100 hue test appear to be more useful than ERG OP implicit time in the evaluation of visual pathway dysfunction in aretinopathic IDDM patients. Not only was it relatively more sensitive and relatively more specific than the ERG, but the 100 hue test was also quicker, less invasive, cheaper, and required less technical support than the ERG; and patients preferred it.

This work was supported by a grant from Scotia Pharmaceuticals Ltd, Woodbridge Meadows, Guildford, Surrey.

1 The Diabetes Control and Complications Trial Research Group. The effect of intensive treatment of diabetes on the development and progression of long-term complications in insulin-dependent diabetes mellitus. $N$ Engl $\mathscr{f} M e d$ 1993; 329: 977-86.

2 Brinchmann-Hansen, Dahl-Jorgensen K, Sandvik L, Hanssen KF. Blood glucose concentrations and progression of diabetic retinopathy: the seven year results of the Oslo study. BMF 1992; 304: 19-22.

3 Roy MS, Gunkel RD, Podgor MJ. Color vision in early diabetic retinopathy. Arch Ophthalmol 1986; 104: 225-8.

4 Jenkins TCA, Cartwright JP. The electroretinogram in minimal diabetic retinopathy. Br f Ophthalmol 1990; 74: minimal

5 Caputo S, Di Leo MAS, Ghirlanda G, Falsini B, Marietta $G$, Porciatti V, et al. Steady-state focal electroretinogram in Type 1 (insulin-dependent) diabetes with no or early retinopathy. Diabetologia 1989; 32: 472A-3A.

6 Hardy KJ, Lipton J, Scase MO, Foster DH, Scarpello JHB. Detection of colour vision abnormalities in uncomplicated type 1 diabetic patients with angiographically normal retinas. $\mathrm{Br} \mathcal{F}$ Ophthalmol 1992; 76: 461-4.

7 Bresnick GH, Korth K, Groo A, Palta M. Electroretinographic potentials predict progression of diabetic retinopathy. Arch Ophthalmol 1984; 102: 1307-11

8 Hardy KJ, Scarpello JHB. The effects of blood glucose control on retinal dysfunction in Type 1 diabetes. Diabetic Med 1992; 9 (suppl 1): 40A

9 Farnsworth D. The Farnsworth-Munsell 100-Hue Test Manual. Baltimore: Munsell Color Company, 1957.

10 International Standardization Committee. Standards for clinical electroretinography. Arch Ophthalmol 1989; 107: 816-9.

11 Kinnear PR. Proposals for scoring and assessing the 100Hue test. Vision Res 1970; 10: 423-33.

12 Verriest G, Van Laethem J, Uvijls A. A new assessment of the normal ranges of the Farnsworth-Munsell 100-Hue test scores. Am $\mathcal{F}$ Ophthalmol 1982; 93: 635-42.

13 Bresnick GH, Palta M. Temporal aspects of the electroretinogram in diabetic retinopathy. Arch Ophthalmol 1987; 105: 660-4.

14 Coupland SG. A comparison of oscillatory potential and pattern electroretinogram measures in diabetic retinopathy. Doc Ophthalmol 1987; 66: 207-18.

15 Verriest G. Further studies on acquired deficiency of color discrimination. F Opt Soc Am 1963; 53: 185-95. 